\title{
Efeito da verminose na resposta imune em caprinos
}

\author{
Efect of verminosis on goat immune response
}

\author{
Marilene Machado Silva ${ }^{1}$; Sebastião Pereira de Faria Jr. ${ }^{1}$; Maria de Fátima Martins ${ }^{1}$;

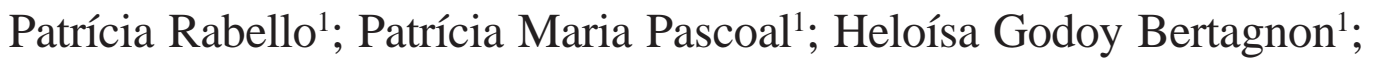 \\ Monika Scheibel ${ }^{1}$; Maurício Garcia ${ }^{1 *}$
}

\begin{abstract}
Resumo
O objetivo deste trabalho foi estudar a resposta imunológica em caprinos com vários graus de verminose gastrintestinal. Foram utilizados 90 animais adultos, naturalmente infectados, divididos em três grupos de 30 animais cada e separados segundo a contagem de ovos por grama de fezes (OPG): grupo I de zero a 500 OPG; grupo II de 501 a 2.000 OPG e o grupo III maior que 2.000 OPG. As variáveis estudadas foram: a dosagem de proteínas séricas totais (PST), avaliada pelo método do biureto; globulinas (Glob), calculada pela diferença entre a proteína total e a albumina sérica; gamaglobulinas (Gglob), medidas pela eletroforese; imunoglobulinas (Ig), dosadas pelo teste da turbidimetria com $\mathrm{ZnSO}_{4}$ e a contagem absoluta de linfócitos (Linfo/mL). Observou-se que em três destes parâmetros (PST, Ig e Linfo/mL) houve queda estatisticamente significativa para o grupo mais infectado. Para a Glob e Gglob a queda não foi significativa. A diminuição destes parâmetros denota um efeito depressor da helmintose sobre o sistema imune humoral. $\mathrm{O}$ fato da dosagem de Glob e Gglob não ser estatisticamente menor pode ser explicado pela ocorrência de uma maior dispersão destes resultados. Conclui-se, assim, que caprinos acometidos de intensa helmintose gastrintestinal (acima de 2000 OPG) mostraram-se imunodeprimidos, com linfopenia e diminuição dos níveis séricos de anticorpos.
\end{abstract}

Palavras chave: Caprinos; Verminose; Imunodepressão.

\begin{abstract}
The purpose of this work was to evaluate the immune response in goats with different degrees of gastrintestinal nematode infection. Ninety adult animals naturally infected were grouped according to the total egg count per feces gram (EPG): group I from zero to 500 EPG, group II from 501 to 2000 and group III above 2000. The parameters studied were serum total protein (STP), evaluated by biuret method; globulin (Glob), calculated by the difference between STP and serum albumin; gammaglobulin (Gglob), estimated throughout electrophoresis; immunoglobulin (Ig), estimated by turbidometry test with $\mathrm{ZnSO}_{4}$ and absolute lymphocyte count (Lymp / ml). It was found statistically decrease in three parameters (STP, Ig and Lymp / ml) for group III. For Glob and Gglob, the decrease found was not statistically significant. These results show a depressor effect of nematode infection on humoral immune system. The intense dispersion of Glob and Gglob data can explain the not significant decrease found in those parameters. It was concluded that goats with intense nematode infection (above 2000 EPG) can show immunedepression, with impairment of lymphocyte count and serum antibody level.
\end{abstract}

Key words: Caprine; Verminosis; Immunossupression.

\footnotetext{
${ }^{1}$ Maurício Garcia. Curso de Medicina Veterinária, Instituto de Ciências da Saúde, Universidade Paulista, Av. Ten. Júlio Prado Neves 965, CEP 02370-000, São Paulo-SP, Fone: (11) 5061-7599E-mail: mauricio@mgar.vet.br

* Autor para correspondência.
} 


\section{Introdução}

No Brasil, tem se notado o crescimento da exploração intensiva de caprinos, fato que tem despertado maior atenção ao controle sanitário dos animais, principalmente em relação as helmintoses gastrintestinais, já que são muito freqüentes e influenciam diretamente a produtividade (TAYLOR et al., 1990; WARUIRU et al., 1994). Nos casos crônicos, os animais tornam-se anoréticos, anêmicos e debilitados (LE JAMBRE, 1995). Além disso, Lloyd (1987) já salientava que os caprinos são mais susceptíveis aos endoparasitas, quando comparados com outras espécies, como os ovinos, por exemplo.

Os helmitos gastrintestinais mais importantes dos pequenos ruminantes são Haemonchus contortus, Ostertagia spp e Trichostrongylus spp. O ciclo de vida destes parasitas é direto, os ovos são liberados com as fezes e desenvolvem-se rapidamente em larvas infectantes. Em circunstâncias ótimas, este desenvolvimento pode levar de quatro a seis semanas e as larvas podem sobreviver na pastagem por meses. A larva infectante é ingerida com a pastagem e desenvolve-se em forma adulta, sendo que em 2 a quatro semanas seus ovos estão presentes nas fezes (UHLINGER, 1996).

A ação destes helmintos no sistema imune tem sido objeto de estudo de alguns pesquisadores. Segundo Rahman e Collins (1991), o Haemonchus sp provocaria leucopenia por linfopenia. Para Baker et al. (1982), os parasitas causariam perdas protéicas por enteropatias e perda de sangue por parasitismo entérico, fato que levaria a uma hipoproteinemia com hipogamaglobulinemia.

Para Soulsby (1985), inúmeros fatores têm sido propostos como causa da imunodepressão em helmintoses, tal como competição antigênica, estimulação de células supressoras não específicas, competição com superfície de macrófagos, modificação do tráfego de linfócitos através dos tecidos parasitados, produção de fatores inibidores da resposta imunológica pelos parasitas e ativação de linfócitos policlonais. Adams e Davies (1982) rela- taram que o tratamento de ovinos infectados por Haemonchus contortus com dexametasona bloqueou a atividade de células supressoras. Klesius et al. (1984), estudando a patogenia da ostertagiose, descreveram que a ação dos parasitas seria responsável pela geração de células T supressoras da resposta imune celular. Aparentemente, os parasitas induziriam uma imunossupressão em seu hospedeiro para poder permanecer livre dos ataques do sistema imune.

As conseqüências da imunodepressão associada a parasitas incluem aumento da susceptibilidade a outros organismos, aumento do desenvolvimento de tumores, eficácia de vacinação reduzida, assim como diminuição da resposta imunológica contra parasitas homólogos (GIBBS, 1992). Para Johnston e Morris (1996), os animais parasitados são mais susceptíveis a doenças causadas por outros agentes infecciosos.

No Brasil praticamente inexistem trabalhos que procuraram estudar o efeito das helmintoses gastrintestinais no sistema imune de caprinos. Assim, o objetivo do trabalho foi contribuir para esse estudo, analisando diferentes parâmetros de imunidade em caprinos naturalmente infectados por helmintos gastrintestinais.

\section{Material e métodos}

Foram utilizados 90 animais da espécie caprina de raças leiteiras, com mais de um ano de idade, sob manejo de semiconfinamento originários de diversas propriedades do Estado de São Paulo, submetidos à infecção natural por helmitos gastrintestinais. Os animais foram divididos em três grupos de 30 animais e escolhidos segundo a contagem de ovos de helmintos por grama de fezes (OPG), da seguinte maneira: grupo I (até 500 OPG), grupo II (de 501 a 2000 OPG) e grupo III (mais de 2000 OPG).

Dos animais foram coletadas fezes em frasco coletoras universal, transportadas para o laboratório sob refrigeração e processadas no mesmo dia. Nestas amostras foi realizada a contagem de ovos em câmara MacMaster (WHITLOCK apud RAHMAN, 
1994). Foi realizada, ainda, a coprocultura para identificação e contagem de larvas, conforme a técnica de Roberts e O’Sullivan (1950).

Também foram coletadas amostras de sangue (com e sem anticoagulante ácido etilenodiamino tetracético - EDTA) por punção da veia jugular, as quais foram transportadas sob refrigeração ao laboratório. No sangue colhido com EDTA, foi realizada a contagem global de leucócitos em câmara de Neubauer através do método do hemocitômetro. A contagem diferencial foi feita através da extensão sangüínea corada pelo corante de Leishman e, após a obtenção da contagem relativa, os números foram transformados em contagem absoluta de linfócitos (HEWITT, 1984).

No soro obtido a partir das amostras sangüíneas colhidas sem EDTA foi realizada a dosagem de proteínas totais, usando-se o reativo de biureto (WEICHSELBAUM, 1946). Em seguida, foi determinada a concentração de albumina usando-se o reativo de verde de bromocresol (DOUMAS; WATSON; BIGGS, 1971). A concentração de globulinas totais foi obtida através da diferença entre a concentração de proteínas totais e a concentração de albumina. Para dosagem de gamaglobulinas, foi realizada a eletroforese de proteínas séricas totais em acetato de celulose (BARTA;POURCIAU, 1984). Também foi empregado o método da turbidimetria com de sulfato de zinco em espectofotômetro, para a estimativa da concentração de imunoglobulinas (McEWAN et al., 1970).

Para o tratamento estatístico, foram consideradas as seguintes variáveis: proteínas totais (em g/ $\mathrm{dL}$ ), globulinas totais (em $\mathrm{g} / \mathrm{dL}$ ), gamaglobulinas avaliadas pela eletroforese (em g/dL), linfócitos totais (em células $/ \mu \mathrm{L}$ ) e imunoglobulinas estimadas pela turbidometria (expressas no valor da absorbância). Tais variáveis foram submetidas à análise de variância (ANOVA) simples, de acordo com os três grupos experimentais. Nos casos em que houve significância no resultado da ANOVA, foi realizada a comparação entre médias dos grupos pelo método de Tukey. Foi realizado, também, o teste de correlação entre as variáveis citadas e os valores de OPG (ZAR, 1996). Os testes estatísticos foram realizados em planilha eletrônica comercial (Microsoft Excel 97), segundo Dretzke e Heilman (1998), sendo considerado um valor de $\mathrm{p}<5 \%$ como significante.

\section{Resultados}

Para todos os parâmetros estudados, encontrouse um comportamento semelhante nos resultados: os valores dos grupos III foram menores que os encontrados nos grupos I e II, os quais apresentaram valores semelhantes. Para as proteínas totais, os animais dos grupos I e II apresentaram valores ao redor de 7 $\mathrm{g} / \mathrm{dL}$, já o grupo III ao redor de $6 \mathrm{~g} / \mathrm{dL}$. As globulinas estiveram em média acima de 3,8 g/dL nos grupos I e II, mas abaixo de 3,4 no grupo III. As gamaglobulinas mostraram-se ao redor de $2,2 \mathrm{~g} / \mathrm{dL}$ nos grupos I e II, mas abaixo de 1,8 no grupo III. Os linfócitos dos animais dos grupos I e II estiveram acima de 4100 céls./ $\mu \mathrm{L}$, mas os animais do grupo III apresentaram média de 2600. Finalmente, a absorbância média do soro dos animais dos grupos I e II, no teste de turbidometria, foi ao redor de 1,5, mas animais do grupo III apresentaram absorbância média de 1,2 (Tabela 1). Nos resultados da cultura de larvas, as porcentagens médias de larvas de Haemonchus sp encontradas foram de 48,4\%, 69\% e $74,1 \%$ respectivamente para os grupos I, II e III. Houve diferença estatisticamente significativa entre o resultado do grupo I e os resultados dos grupos II e III, estes últimos estatisticamente iguais. 
Tabela 1 - Valores médios (e desvio padrão) de parâmetros imunológicos de caprinos naturalmente infectados por helmintos gastrintestinais

\begin{tabular}{cccc}
\hline Parâmetro & $\begin{array}{c}\text { Grupo I } \\
\text { Zero a 500 OPG }\end{array}$ & $\begin{array}{c}\text { Grupo II } \\
\mathbf{5 0 1} \text { a 2000 OPG }\end{array}$ & $\begin{array}{c}\text { Grupo III } \\
\text { mais de 2000 OPG }\end{array}$ \\
\hline $\begin{array}{c}\text { Proteínas totais } \\
\text { (g/dL) }\end{array}$ & $6,89^{\mathrm{a}}$ & $7,02^{\mathrm{a}}$ & $5,94^{\mathrm{b}}$ \\
& $(0,74)$ & $(1,02)$ & $(0,12)$ \\
Globulinas & $3,78^{\mathrm{a}}$ & $3,94^{\mathrm{a}}$ & $3,41^{\mathrm{a}}$ \\
(g/dL) & $(0,73)$ & $(1,73)$ & $(1,00)$ \\
& & & \\
Gamaglobulinas & $2,23^{\mathrm{a}}$ & $2,22^{\mathrm{a}}$ & $1,82^{\mathrm{a}}$ \\
(g/dL) & $(0,60)$ & $(0,98)$ & $(0,69)$ \\
& & & \\
Linfócitos & $4,09^{\mathrm{a}}$ & $4,33^{\mathrm{a}}$ & $2,61^{\mathrm{b}}$ \\
$\left(10^{3}\right.$ céls./ $\left.\mu \mathrm{L}\right)$ & $(1,56)$ & $(1,56)$ & $(0,99)$ \\
& & & $1,24^{\mathrm{b}}$ \\
Imunoglobulinas & $1,48^{\mathrm{a}}$ & $1,50^{\mathrm{a}}$ & $(0,05)$ \\
(absorbância) & $(0,18)$ & $(0,33)$ & \\
\hline
\end{tabular}

${ }^{a b}$ Letras diferentes indicam diferenças estatisticamente significantes; OPG = ovos por grama de fezes

Quando foi feito o teste de correlação com a contagem de ovos (OPG), encontrou-se uma correlação negativa em todas as variáveis, ou seja, quanto maior a contagem de OPG, menor o valor da variável estudada (Tabela 2).

Tabela 2 - Valores do teste de correlação (r) entre os resultados de parâmetros imunológicos de caprinos naturalmente infectados por helmintos gastrintestinais com a respectiva contagem de ovos na fezes (OPG).

\begin{tabular}{cc}
\hline Correlação & Valor de r \\
\hline Proteínas totais x OPG & $-0,39^{*}$ \\
Globulinas x OPG & $-0,14$ \\
Gamaglobulinas x OPG & $-0,13$ \\
Linfócitos x OPG & $-0,36^{*}$ \\
Imunoglobulinas x OPG & $-0,36^{*}$ \\
\hline
\end{tabular}

*correlação estatisticamente significante

\section{Discussão}

O sistema imune desempenha importante papel na defesa do organismo frente às diversas agressões ambientais. Muitas enfermidades se manifestam quando este sistema não consegue satisfatoriamente controlar, por exemplo, agentes infecciosos patogênicos. Desta forma, avaliar o impacto das diversas enfermidades no sistema imune é preocupação freqüente dos pesquisadores de todo o mundo. Todavia, os constantes achados na área da imunologia fazem com que freqüentemente novos mecanismos de defesa sejam descobertos de sorte que não existe um método universalmente aceito entre a comunidade científica para a avaliação da condição do sistema imune (SCHULTZ; ADAMS, 1978). Desta forma, os resultados aqui encontrados deram uma contribuição neste sentido, demonstrando que animais com intensa parasitose gastrintestinal apresentam seu sistema imune comprometido. $\mathrm{O}$ fato de não ter sido encontrada diferença estatisticamente significativa para as variáveis globulina e gamaglobulina pode ser explicado em parte pela grande dispersão encontrada nestes resultados. Os valores dos desvios padrão destas variáveis foram proporcionalmente maiores que nas outras variáveis. Assim, é razoável supor que com uma amostragem maior, as diferenças encontradas teriam sido estatisticamente significantes.

Os resultados encontrados estão de acordo com os relatos de Rahman e Collins (1991), que encontrou linfopenia em caprinos com hemoncose, e de Baker et al. (1982), que descreveram hipoproteinemia com hipogamaglobulinemia. Ressalta-se que neste trabalho, nos animais do grupo III, que se encontraram imunodeprimidos, houve um predomínio absoluto de infecção pelo gênero Haemonchus.

Roitt (1994) salientou que estados nutricionais precários interferem no sistema imune e Le Jambre (1995) e Johnston e Morris (1996) demonstraram que a verminose pode provocar tal estado nutricional, devido à diminuição da absorção de nutrientes, anorexia e anemia.

Não foi possível, porém, estabelecer a relação 
"causa x efeito", isto é, não foi possível determinar se a infecção parasitária intensa provocou a imunodepressão ou se os animais tornaram-se intensamente parasitados por estarem previamente imunodeprimidos. Alguns autores relataram que a verminose poderia provocar uma imunodepressão (ADAMS; DAVIES, 1982; KLESIUS et al., 1984), todavia este trabalho não permitiu confirmar ou refutar tais relatos.

\section{Referências}

ADAMS, D. B.; DAVIES, H. I. Enhanced resistance to infection with Haemonchus coLntortus in sheep treated with a corticosteroid. International Journal for Parasitology, Elmsford, v.12, n.6, p.523-9, 1982.

BAKER, D. C. et al. Hemoparasitism, humoral immunodeficiency, and an IgG1 fragment in a cow. Journal of the American Veterinary Medical Association, Schaumburg, v.181, n.5, p.480-483, 1982.

BARTA, O.; POURCIAU, S. S. Electrophoresis. In: BARTA, O. laboratory techniques of veterinary clinical immunology. Illinois: Charles C. Thomas, 1984. p.116-22.

DOUMAS, B. T.; WATSON, W. A.; BIGGS, H. G. Albumin standards and the measurement of serum albumin with bromcresol green. Clinica Chimica Acta, Amsterdam, v.31, n.1, p. 87-96, 1971.

DRETZKE, B. J.; HEILMAN, K. A. Statistics with microsoft excel. New Jersey: Pratice Hall, 1998.

GIBBS, H. C. The effects of subclinical disease on bovine gastrointestinal nematodiasis. The Compendium on Continuing Education for the Practicing Veterinarian, Princeton, v.14, n.5, p.669-677, 1992.

HEWITT, S. G. Haematology. In: GRAY.D.E. Manual of veterinary investigation, laboratory techniques. 3. ed. London: Her Majesty's Stationery Office,1984. v.2, p. 72-100.

JOHNSTON, J. K.; MORRIS, D. D. Alterations in Blood Proteins. In: SMITH,B.P. (Ed.). Large Animal Internal Medicine. 2.ed. Saint Louis: Mosby, 1996. p. 489-97.

KLESIUS, P. H. et al. Lymphocyte reactivity to Ostertagia ostertagi $\mathrm{L}_{3}$ antigen in type I ostertagiasis. American Journal of Veterinary Research, Chicago, v.45, n.2, p.230-3, 1984.

LE JAMBRE, L. F. Relationship of blood loss to worm numbers, biomass and egg production in Haemonchus infected sheep. International Journal for Parasitology, Elmsford, v.25, n.3, p.269-73, 1995.

LLOYD, S. Endoparasitic disease in goats. Goat Veterinary Society Journal, Cambridge, v.8, n.1, p.32-9, 1987.

McEWAN, A. D. et al. A turbidity test for the estimation of immune globulin levels in neonatal calf serum. Clinica Chimica Acta, Amsterdam, v.27, n.1, p.155-63, 1970.

RAHMAN, W. A. Effect of subclinical Eimeria species infections in tropical goats subsequently challenged with caprine Haemonchus contortus. Veterinary Record, London, v.134, n.5, p.235-237, 1994.

RAHMAN, W. A.; COLliNS, G. H. Changes in liveweight gain and blood constituents in experimental infection of goats with a goat-derived compared with a sheep-derived strain of Haemonchus contortus. Veterinary Parasitology, Amsterdam, v.38, p.145-53, 1991.

ROBERTS, F. H. S.; O'SULLIVAN, J. P. Methods for egg counts and larval cultures for strongyles infesting the gastrointestinal tract of cattle. Australian o Agricultural Research, Victoria, v.1, p.99-102, 1950.

ROITT, I. Control mechanisms. In: Essential immunology. 8.ed. London: Blackwell, 1994. p.194-214.

SCHULTZ,R.D.; ADAMS, L. S. Immunologic methods for the detection of humoral and cellular immunity. Veterinary Clinics of North America, Philadelphia,. v.8, n.4, p.721-53, 1978.

SOULSBY, E. J. L. Advances in immunoparasitology. Veterinary Parasitology, Amsterdam, v.18, p.303-319, 1985.

TAYLOR, M. A. et al. Clinical observations, diagnosis and control of Haemonchus contortus infections in periparturient ewes. Veterinary Record, London, v.126, p.555-556, 1990.

UHLINGER, C. A. Parasite control programs. In: SMITH, B. P. Large Animal Internal Medicine. 2.ed. St Louis: Mosby, 1996. p.1685-709.

WARUIRU, R. M. et al.. Differential resistance among secondary challenges of Haemonchus contortus. Bulletin of Animal Health and Production in Africa, Nairobi , v.42, n.3, p.193-197, 1994.

WEICHSELBAUM, C. T. E. An accurate and rapid method for determination of proteins in small amounts of blood serum and plasma. American Journal of Clinical Pathology, Philadelphia, v.16, n.3, p.40-49, 1946.

ZAR, J. H. Biostatistical analysis. 3.ed. New Jersey: Practice Hall, 1996. 
